\title{
Sensitive Extractional Colorimetric Analysis of Fexofenadine Hydrochloride and Irbesartan Bases Through Acid-Dye Complexation Using Naphthol Blue Black in Pure Form and Pharmaceuticals
}

\author{
Safwan Ashour*, Roula Bayram \\ Analytical Chemistry Laboratory, Department of Chemistry, Faculty of Sciences, University of Aleppo, Aleppo, Syria
}

Email address:

profashour@hotmail.com (S. Ashour)

${ }^{*}$ Corresponding author

\section{To cite this article:}

Safwan Ashour, Roula Bayram. Sensitive Extractional Colorimetric Analysis of Fexofenadine Hydrochloride and Irbesartan Bases Through Acid-Dye Complexation Using Naphthol Blue Black in Pure Form and Pharmaceuticals. Modern Chemistry. Vol. 5, No. 6, 2017, pp. 93-100. doi: $10.11648 /$ j.mc.20170506.12

Received: January 25, 2017; Accepted: February 10, 2017; Published: November 28, 2017

\begin{abstract}
A simple, accurate and sensitive method has been presented for the determination of fexofenadine hydrochloride (FEX) and irbesartan (IRB) in bulk and pharmaceutical preparations. The method is based on the reaction of the above cited drugs with naphthol blue black (NBB) dye in solutions containing Britton buffer to form ion-pair complexes extractable with chloroform and subsequently measured spectrophotometrically at $625 \mathrm{~nm}$. All the reaction conditions for the proposed methods have been studied. The reactions were extremely rapid at room temperature and the absorbance values remained unchanged for at least $24 \mathrm{hrs}$. Beer's law was obeyed in the concentration ranges $2.7-53.8$ and 10-244 $\mu \mathrm{g} \mathrm{mL}^{-1}$ with detection limit of 0.013 and $0.75 \mu \mathrm{g} \mathrm{mL}^{-1}$ for FEX and IRB, respectively. The proposed methods were applied successfully for the determination of FEX and IRB in pharmaceutical formulations. Interferences of the other ingredients and excipients were not observed. The results obtained were compared statistically with those obtained by the official method and showed no significant differences regarding accuracy and precision.
\end{abstract}

Keywords: Extractive Colorimetry, Fexofenadine Hydrochloride, Irbesartan, Naphthol Blue Black, Pharmaceuticals

\section{Introduction}

Fexofenadine (Figure 1), $\alpha, \alpha$-dimethyl-4-[1-hydroxy-4[4- (hydroxydiphenyl-methyl)-1-piperidinyl] butyl]-benzene acetic acid [1] is the active carboxylic acid analogue of the antihistamine terfenadine. Fexofenadine is a second generation antihistamine drug useful to available treatments of allergic diseases with a wide margin of safety [2]. The drug is official in BP [3] and USP [4], which describe HPLC methods for the assay of fexofenadine hydrochloride. Several analytical methods for the determination of fexofenadine hydrochloride in pharmaceutical formulations have been reported including high performance liquid chromatography [5-8], spectrophotometry [8-12], conductometry [13], extractive spectrophotometry with bromothymol blue, bromocresol green, bromocresol purple and bromophenol blue [13, 14], spectrofluorometry [15], potentiometry [16] and capillary electrophoresis [17, 18]. Fexofenadine hydrochloride has been determined in combination with other drugs using high performance liquid chromatography [1923], high performance thin layer chromatography [24] and spectrophotometry [25-27] in combined dosage forms.

Irbesartan (Figure 1), an anti-hypertensive is chemically designated as 2-butyl-3-[[4-[2- (2H-tetrazol-5yl)phenyl]phenyl]methyl]-1,3-diazaspiro[4.4]non-1-en-4-one. It is used for the treatment of hypertension [3]. The drug is official in BP [3] and USP [4], which describe HPLC methods for the assay of irbesartan. Few methods have been described for the determination of irbesartan in pharmaceutical dosage forms by HPLC [28-32], extractive 
spectrophotometry with Picric acid, bromocresol green, bromothymol blue, cobalt thiocyanate and molybdenum (V) thiocyanate [33], spectrophotometry [34-36] and HPTLC [37]. Several HPLC [38-45], spectrophotometry [44-50] and capillary electrophoresis methods $[51,52]$ are reported in the literature for the determination of irbesartan in combined pharmaceutical formulations.

Extractive spectrophotometric procedures are popular for their sensitivity in the assay of drugs. Therefore, ion-pair extractive spectrophotometry has received considerable attention for the quantitative determination of many pharmaceutical compounds $[13,14,33,53-55]$. So far, there has been no ion-pair extractive spectrophotometry method reported for an estimation of fexofenadine hydrochloride and irbesartan with naphthol blue black. Fexofenadine and irbesartan have basic cationic nitrogen reacts with anionic dye at a suitable $\mathrm{pH}$, to form highly colored chloroform extractable ion pair complex. Therefore, this paper suggests simple and sensitive colorimetric procedures for the determination of fexofenadine and irbesartan in tablets and capsules. The methods are based on the ability of the cited drugs to form ion-pair complex with naphthol blue black, as acidic dye. Optimum conditions were established and the methods were validated for linearity.

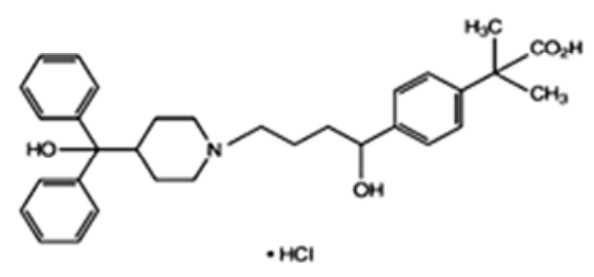

(a)

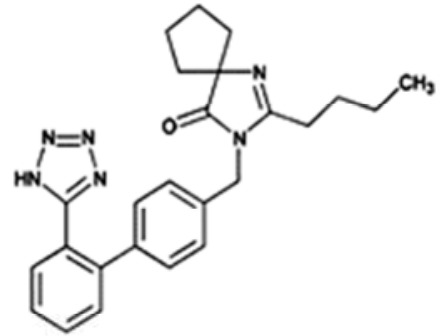

(b)

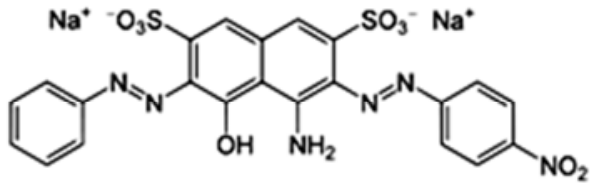

(c)

Figure 1. Chemical structure of fexofenadine hydrochloride (a), irbesartan (b) and naphthol blue black (c).

\section{Materials and Methods}

\subsection{Instrumentation}

A Jasco V-530 UV-VIS spectrophotometer (Japan) provided with $1 \mathrm{~cm}$ matched quartz cells was used for all absorbance measurements under the following operating conditions: scan speed medium $(400 \mathrm{~nm} / \mathrm{min})$, scan range 500-700 nm and slit width $2 \mathrm{~nm}$. Spectra were automatically obtained by Jasco system software. A pH meter model SuntexSP 701 (Taiwan) equipped with combined glass $\mathrm{pH}$ electrode was used. The desired temperature was maintained at $20^{\circ} \mathrm{C}$.

\subsection{Reagents and Drugs}

Pharmaceutical grade fexofenadine hydrochloride (FEX) was obtained from Chem Pharma, India, and used after its purity was determined which found to be $100.05 \%$ according to BP [3]. Irbesartan (IRB) was obtained from Cipex Specialities Pvt Ltd, India. Its purity was found to be $99.67 \%$ according to BP [3]. Tablets and capsules containing fexofenadine hydrochloride and irbesartan were purchased from Syrian market. All chemicals and solvents used were of analytical reagent grade of E. Merck (Germany). Absolute methanol and bi-distilled water were used. Naphthol blue black (NBB) (Fig. 1) was prepared daily as $1 \times 10^{-3} \mathrm{M}$ in bidistilled water. Britton buffer solutions ( $\mathrm{pH}$ range from 1.3 to 4.0) were prepared by mixing specific volumes of acetic acid $0.2 \mathrm{M}$, phosphoric acid $0.2 \mathrm{M}$ and boric acid $0.2 \mathrm{M}$.

\subsection{Standard Stock Solutions}

$1 \times 10^{-3} \mathrm{M}$ solution of pure FEX was prepared in bi-distilled water. $1 \times 10^{-3} \mathrm{M}$ solution of pure IRB was prepared by dissolving the appropriate weight of IRB in $5 \mathrm{~mL}$ of glacial acetic acid in $100 \mathrm{~mL}$ volumetric flask, the volume was then diluted to the mark with bi-distilled water. The solutions were stored in dark bottles and kept in the refrigerator for not more than 10 days. Other concentrations of working solutions were then prepared by suitable dilution of the stock solution with bi-distilled water.

\subsection{Recommended Procedures}

\subsubsection{FEX Method}

Into a series of $50 \mathrm{~mL}$ separating funnels, $2 \mathrm{~mL}$ of buffer of pH 2.4 and $5 \mathrm{~mL}$ of $1 \times 10^{-3} \mathrm{M} \mathrm{NBB}$ solution were added. Varying aliquots $(50-1000 \mu \mathrm{L})$ of a standard FEX $\left(1 \times 10^{-3} \mathrm{M}\right)$ solution were accurately transferred to each funnel. The funnels were shaken vigorously with $10 \mathrm{~mL}$ chloroform for 2 min, and then allowed to stand for clear separation of the two phases. The separated organic phase was transferred to a beaker, dried over anhydrous sodium sulfate and transferred to a $10 \mathrm{~mL}$ volumetric flask. Then the combined extract was made up to the mark with chloroform. The absorbance of the blue colored ion-pair complex was measured at $625 \mathrm{~nm}$ against the reagent blank.

\subsubsection{IRB Method}

Into a series of $50 \mathrm{~mL}$ separating funnels, $5 \mathrm{~mL}$ of buffer solution of $\mathrm{pH} 1.5$ and $4 \mathrm{~mL}$ of $1 \times 10^{-3} \mathrm{M} \mathrm{NBB}$ solution were added. An appropriate volume of $1 \times 10^{-3} \mathrm{M}$ standard IRB solution $(0.24-5.73 \mathrm{~mL})$ was added to each funnel and mixed well. The funnels were shaken vigorously with $10 \mathrm{~mL}$ chloroform for $2 \mathrm{~min}$, and then allowed to stand for clear separation of the two phases. The separated organic phase was transferred to a $50 \mathrm{~mL}$ beaker, dried over anhydrous 
sodium sulfate, and transferred to a $10 \mathrm{~mL}$ volumetric flask. Then the combined extract was made up to the mark with chloroform and mixed. The absorbance of the solution was measured at $625 \mathrm{~nm}$ against the reagent blank.

\subsubsection{Procedure for Dosage Forms}

Twenty tablets or the contents of 20 capsules containing FEX or IRB were weighed and finely powdered. In the case of FEX, an amount of the powder equivalent to $100 \mathrm{mg}$ of FEX was weighed into a $100 \mathrm{~mL}$ volumetric flask, $30 \mathrm{~mL}$ methanol was then added and sonicated for about $5 \mathrm{~min}$. The volume was diluted to the mark with methanol, mixed well and filtered. The combined filtrate was evaporated to the dryness. The remaining portion of the solution was dissolved with bi-distilled water in a $100 \mathrm{~mL}$ volumetric flask, and the resulting solution was used for analysis by the recommended procedure in the concentration range mentioned above.

In the case of IRB, an amount of the powder equivalent to $25 \mathrm{mg}$ of IRB was weighed into a $25 \mathrm{~mL}$ volumetric flask, 5 $\mathrm{mL}$ of glacial acetic acid was then added and mixed for about $15 \mathrm{~min}$. The volume was diluted to the mark with bi-distilled water, mixed well and filtered. The general procedure was then followed in the concentration range mentioned above.

\subsubsection{Procedure for Stoichiometric Ratio}

The reaction stoichiometry between the studied drugs and NBB has been determined spectrophotometrically by applying molar ratio and continuous variation methods. In the former method, equimolar solutions of the studied drugs and NBB $\left(1 \times 10^{-3} \mathrm{M}\right)$ were used. Different aliquots of NBB were added to fixed aliquots of drug solution -total volume $10 \mathrm{~mL}$ - and the absorbance was measured at $625 \mathrm{~nm}$ against the reagent blanks treated similarly. While in the latter method, a series of drug-NBB solutions was kept at $2.0 \mathrm{~mL}$ $(0: 2,0.2: 1.8,0.4: 1.6, \ldots \ldots, 2: 0)$ where $\mathrm{C}_{\mathrm{FEX}}+\mathrm{C}_{\mathrm{NBB}}=2 \times 10^{-4} \mathrm{M}$ and $\mathrm{C}_{\mathrm{IRB}}+\mathrm{C}_{\mathrm{NBB}}=6 \times 10^{-4} \mathrm{M}$. The reagent was mixed in various proportions and then diluted to volume in a $10 \mathrm{~mL}$ calibrated flask with chloroform. The absorbance of the resulting solutions was measured at $625 \mathrm{~nm}$ against the reagent blanks treated similarly.

\section{Results and Discussion}

\subsection{Absorption Spectra}

FEX and IRB form ion-pair complexes in acidic buffer with NBB dye and these complexes are quantitatively extracted into chloroform. Absorption spectra of the blue FEX-NBB and IRB-NBB ion-pair complexes extracted into chloroform with its $\lambda_{\max }$ at $625 \mathrm{~nm}$, respectively, are shown in Figure 2. The colorless reagent blank under similar conditions showed negligible absorption.

Containing cationic nitrogen, the cited drugs react with NBB to form ion-pair complexes between the basic nitrogen of FEX and IRB in Britton buffer and NBB. Each drug-NBB complex, with two oppositely charged ions, behaves as a single unit held together by an electrostatic force of attraction. The complex is quantitatively extracted into chloroform.

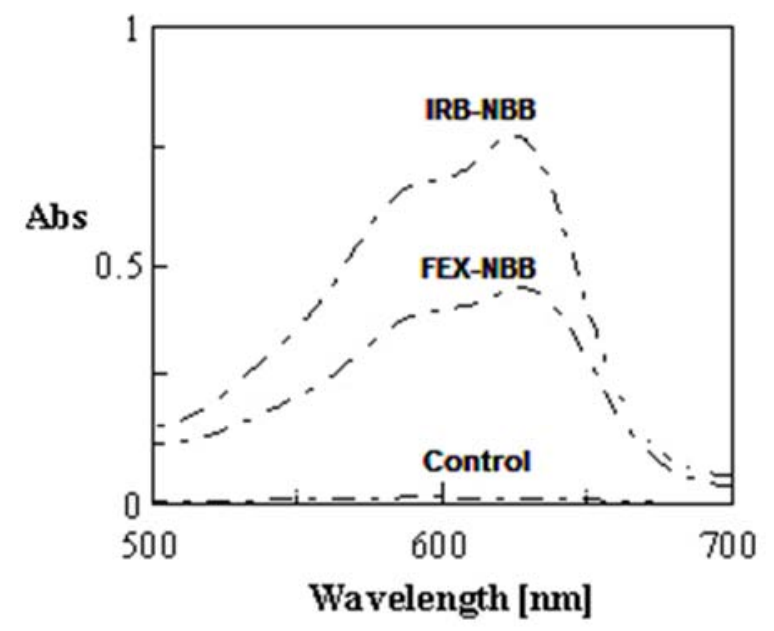

Figure 2. Absorption spectra of: FEX-NBB complex $\left(20 \mu \mathrm{g} \mathrm{mL}^{-1}\right.$ of FEX) and IRB-NBB complex $\left(90 \mu \mathrm{g} \mathrm{mL}^{-1}\right)$ against their respective blank $v$ s. chloroform.

\subsection{Optimization of Variables}

Optimum conditions necessary for rapid and quantitative formation of colored ion-pair complexes with maximum stability and sensitivity were established by a number of preliminary experiments. Britton buffer was found to be suitable for NBB method. Chloroform was preferred to other solvents (carbon tetrachloride, dichloromethane, and ether) for both methods for its selective and quantitative extraction. Optimum conditions were fixed by varying one parameter at a time while keeping other parameters constant and observing its effect on the absorbance at $625 \mathrm{~nm}$ for FEX-NBB and IRB-NBB.

The effect of $\mathrm{pH}$ and volume of buffer was studied by extracting the colored complex species at different $\mathrm{pH}$ value and volume of buffer. Maximal absorbance was observed at the pH 2.4 and 1.5 using 2 and $4 \mathrm{~mL}$ of Britton buffer for FEX and IRB, respectively, (Figures 3 and 4).

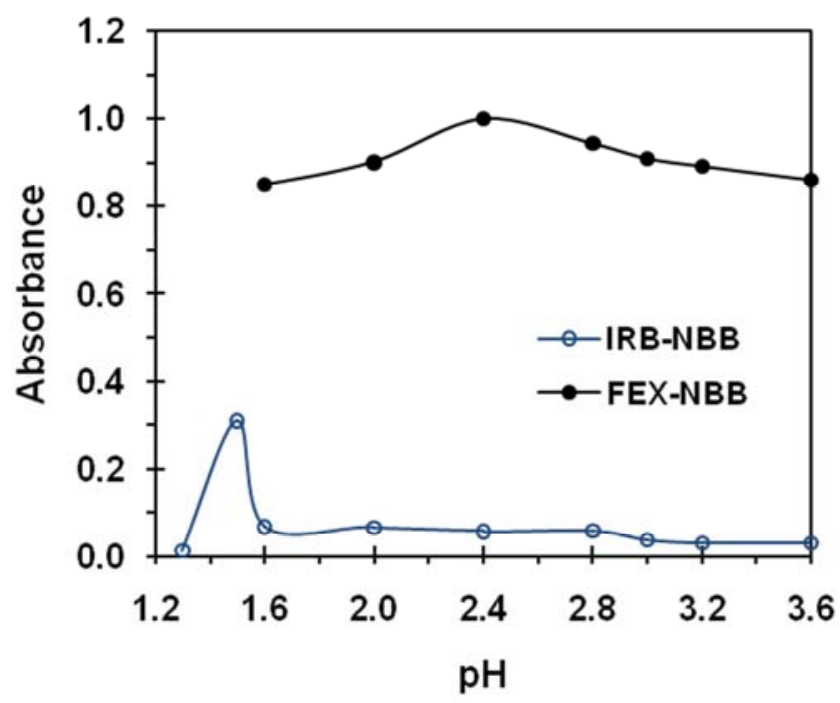

Figure 3. Effect of $p H$ and volume of buffer on the absorbance at $\lambda_{\max }$ of

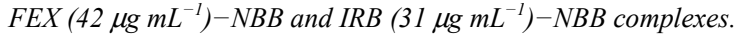




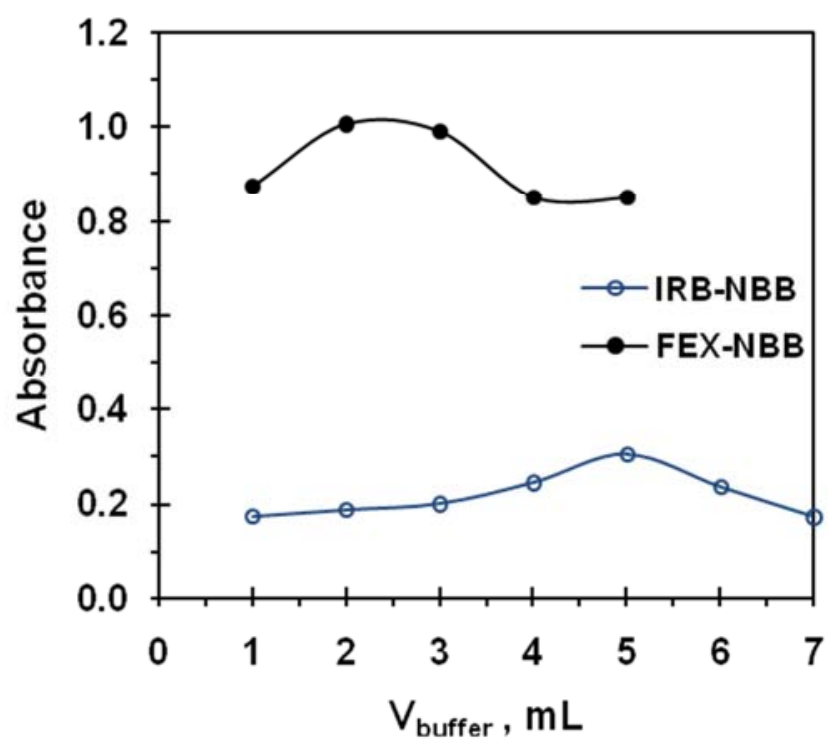

Figure 4. Effect of volume buffer on the absorbance of at $\lambda_{\max }$ of FEX (42 $\mu \mathrm{g}$ $\left.m L^{-1}\right)-N B B$ at $p H 2.4$ and IRB $\left(37 \mu g m L^{-1}\right)-N B B$ at $p H 1.5$.

A volume of 5 and $4 \mathrm{~mL}$ of $1 \times 10^{-3} \mathrm{M} \mathrm{NBB}$ was found to be optimal for complete complexation between FEX and $\mathrm{NBB}$, and IRB and dye, respectively, since the absorbance at maximum wavelength was found to be maxima at the mentioned volumes. The effect of the reagent's concentration on the absorbance of the colored complex species is shown in Figure 5.

\subsection{Stoichiometric Relationship}

The stoichiometric ratio and conditional stability constant

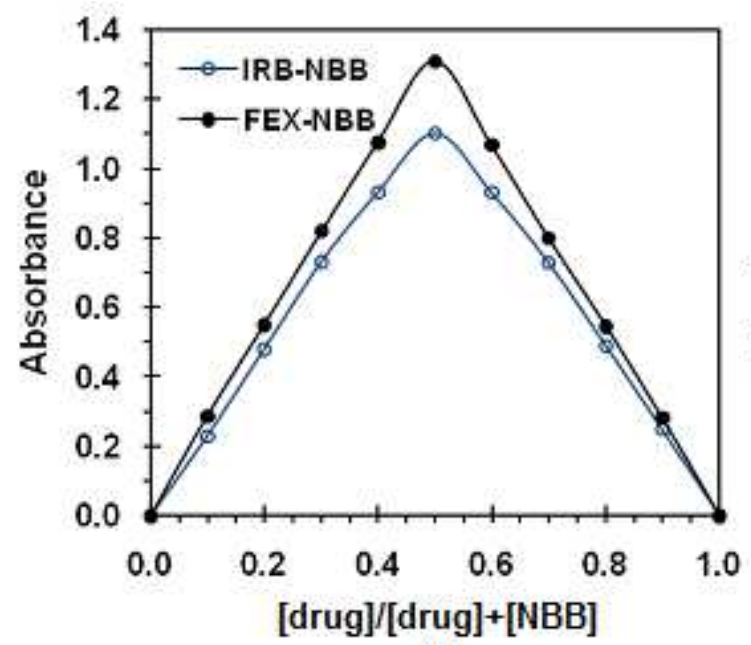

(a) of the FEX-NBB or IRB-NBB complex formed were determined by applying Job's method of continuous variation and molar ratio method [56]. In all cases of Job's method (Figure 6a), the plots reached maximum value at a mole fraction of 0.5 , indicating that ion pair complex with drug to dye ratio 1:1 are formed. Also, the plots of the mole ratio between drug and reagent versus the absorbance values were prepared (Figure 6b), and the results revealed that the formation of ion-pair complex between drug and reagent followed a 1:1 reaction stoichiometry.

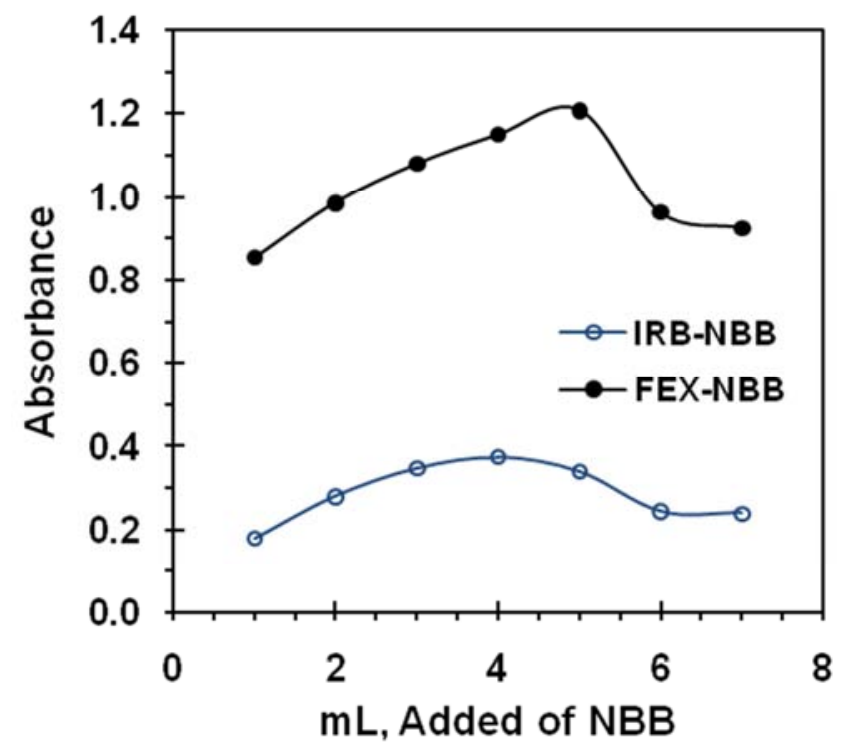

Figure 5. Effect of reagent volume on the formation of the colored ion-pair complexes FEX $\left(50 \mu \mathrm{g} \mathrm{LL}^{-1}\right)-N B B$ and IRB $\left(44 \mu \mathrm{g} \mathrm{LL}^{-1}\right)-N B B$.

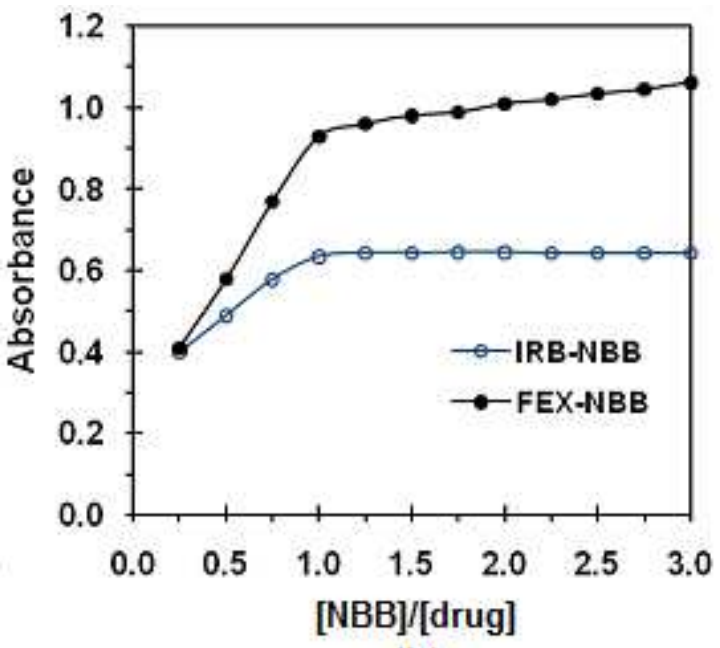

(b)

Figure 6. (a) Job's method of continuous variation of drug-NBB complexes, $C_{F E X}+C_{N B B}=2 \times 10^{-4} M$ and $C_{I R B}+C_{N B B}=6 \times 10^{-4} M$, (b) mole-ratio method of drug-NBB complexes $\left(C_{F E X}=5 \times 10^{-5} \mathrm{M}, C_{I R B}=3 \times 10^{-4} \mathrm{M}\right)$.

\subsection{Conditional Stability Constant $\left(K_{f}\right)$ of Ion-pair}

The conditional stability constant $\left(K_{\mathrm{f}}\right)$ of the ionassociation complex formed by FEX or IRB with NBB, was calculated from the continuous variation data using the equation (1).

$$
K_{f}=\frac{A / A_{m}}{\left[1-\left(A / A_{\max }\right)\right]^{n+2} \cdot C_{M}(n)^{n}}
$$

where $A$ is the maximum observed absorbance and $A_{m}$ is the 
absorbance value when all the amount of drug is associated. $C_{M}$ is the mole concentration of drug at the maximum absorbance and $n$ is the combination ratio of the ion-pair considered [57]. The $\log K_{f}$ values obtained for the FEXNBB and IRB-NBB ion-pair, are 6.52 and 7.23, respectively.

\subsection{Validation of the Method}

A linear relationship was found between the absorbance at $\lambda_{\max }$ and the concentration of FEX and IRB in the range of 2.7-53.8 and 10-244 $\mu \mathrm{g} \mathrm{mL} \mathrm{m}^{-1}$, respectively. Regression analysis of the Beer's law plots at $\lambda_{\max }$ reveals a good correlation (Table 1). The graphs show negligible intercept and are described by the regression equation, $A=m C+b$ (where $A$ is absorbance of $1 \mathrm{~cm}$ layer, $m$ is the slope, $b$ is the intercept and $C$ is the concentration of the measured solution in $\mu \mathrm{g} \mathrm{mL}^{-1}$ ) obtained by the least-squares method [58].

Table 1. Statistical data of the regression equations for the determination of FEX and IRB with the proposed method.

\begin{tabular}{lll}
\hline Parameter & FEX & IRB \\
\hline$\left.\lambda_{\text {max }} \mathrm{nm}\right)$ & 625 & 625 \\
Beer's law range $\left(\mu \mathrm{g} \mathrm{mL}^{-1}\right)$ & $2.7-53.8$ & $10-244$ \\
Ringbom optimum range $\left(\mu \mathrm{g} \mathrm{mL}^{-1}\right)$ & $8.0-40.0$ & $16.0-120$ \\
LOD $\left(\mu \mathrm{g} \mathrm{mL}^{-1}\right)$ & 0.013 & 0.750 \\
LOQ $\left(\mu \mathrm{g} \mathrm{mL}^{-1}\right)$ & 0.24 & 1.36 \\
$\varepsilon\left(\mathrm{L} \mathrm{mol}{ }^{-1} \mathrm{~cm}^{-1}\right)$ & $1.40 \times 10^{4}$ & $0.36 \times 10^{4}$ \\
Stability $(\mathrm{hrs})$ up to $30^{\circ} \mathrm{C}$ & 72 & 24 \\
Sandell's sensitivity $\left(\mu \mathrm{g} \mathrm{cm}{ }^{-2}\right)$ & 0.073 & 0.238 \\
Regression equation*: Slope $(m)$ & 0.0220 & 0.0086 \\
Intercept $(b)$ & 0.0751 & -0.0022 \\
Correlation coefficient $(r)$ & 0.9998 & 0.9998 \\
Range of error\% & \pm 1.37 & \pm 0.82 \\
\hline
\end{tabular}

${ }^{*} A=m C+b$, where $A$ is absorbance and $C$ is the concentration $\left(\mu \mathrm{g} \mathrm{mL} L^{-1}\right)$.

The minimum level at which the investigated compound can be reliably detected (limit of detection, LOD) and quantified (limit of quantitation, LOQ) was determined experimentally for the proposed methods. The LOD was expressed as the concentration of drug that generated a response to three times of the signal to-noise $(\mathrm{S} / \mathrm{N})$ ratio, and the LOQ was 10 times of the $\mathrm{S} / \mathrm{N}$ ratio. The LOD of FEX and IRB attained as defined by IUPAC [59], LOD ${ }_{(k=3)}=k \times S_{\mathrm{a}} / b$ (where $b$ is the slope of the calibration curve and $S_{\mathrm{a}}$ is the standard deviation of the intercept), was found to be 0.013 and $0.750 \mu \mathrm{g} \mathrm{mL}^{-1}$ for FEX and IRB, respectively. The LOQ was also attained according to the IUPAC definition, $\mathrm{LOQ}_{(k=10)}=k \times S_{\mathrm{a}} / b$, and was found to be 0.24 and $1.36 \mu \mathrm{g} \mathrm{mL}^{-}$ 1 , respectively. Sandell's index represents the number of micrograms or nanograms of the determinant per milliliter of a solution having an absorbance of 0.002 for the cell path length of $1 \mathrm{~cm}$ and is a suitable parameter for expressing and comparing the sensitivity of developed spectrophotometric method. For more accurate analysis, Ringbom optimum concentration range was calculated [60]. Table 1 shows the analytical parameters for the determination of FEX and IRB using the proposed method.

The accuracy and precision of the proposed methods was established by measuring the content of FEX or IRB in pure form at four different concentration levels. The intra-day precision of the proposed method was performed by carrying out six independent analyses at each concentration during the same day. In the same manner, the inter-day precision was also evaluated by measuring the cited drugs content at each concentration level on 5 consecutive days by the proposed method (Table 2). The RSD\% values of intra-day and interday studies showed that the precision was good (Table 2). The accuracy of an analytical method expresses the closeness between the reference value and the found value. Accuracy was evaluated as percentage relative error $\left(\mathrm{E}_{\mathrm{r}} \%\right)$ between the measured concentrations and taken concentrations for FEX and IRB (Bias\%). The results obtained are compiled in Table 2 and show that the accuracy was good.

Table 2. Analysis of FEX and IRB with NBB in bulk powder.

\begin{tabular}{|c|c|c|c|c|c|c|c|}
\hline \multirow{2}{*}{ Method } & \multirow{2}{*}{ Drug taken $\left(\mu \mathrm{g} \mathrm{mL^{-1 } )}\right.$} & \multicolumn{3}{|l|}{ Intra-day $(n=6)$} & \multicolumn{3}{|l|}{ Inter-day $(n=6)$} \\
\hline & & Found \pm SD $\left(\mu \mathrm{g} \mathrm{mL}^{-1}\right)$ & RSD\% & $\mathbf{E}_{\mathbf{r}} \%$ & Found \pm SD $\left(\mu \mathrm{g} \mathrm{mL}^{-1}\right)$ & RSD $\%$ & $\mathrm{E}_{\mathbf{r}} \%$ \\
\hline \multirow{4}{*}{ FEX-NBB } & 5.00 & $5.08 \pm 0.06$ & 1.18 & 1.60 & $5.08 \pm 0.07$ & 1.38 & 1.60 \\
\hline & 10.00 & $9.97 \pm 0.08$ & 0.80 & -0.30 & $9.98 \pm 0.06$ & 0.60 & -0.20 \\
\hline & 20.00 & $20.25 \pm 0.12$ & 0.59 & 1.25 & $20.20 \pm 0.10$ & 0.49 & 1.00 \\
\hline & 40.00 & $40.12 \pm 0.21$ & 0.52 & 0.30 & $40.07 \pm 0.19$ & 0.47 & 0.18 \\
\hline \multirow{4}{*}{ IRB-NBB } & 10.00 & $9.98 \pm 0.14$ & 1.40 & -0.20 & $9.97 \pm 0.10$ & 1.00 & -0.30 \\
\hline & 50.0 & $50.72 \pm 0.56$ & 1.10 & 1.44 & $50.69 \pm 0.47$ & 0.93 & 1.38 \\
\hline & 100.0 & $100.08 \pm 1.03$ & 1.03 & 0.08 & $100.02 \pm 0.90$ & 0.90 & 0.02 \\
\hline & 200.0 & $200.05 \pm 1.32$ & 0.66 & 0.02 & $200.03 \pm 1.28$ & 0.64 & 0.01 \\
\hline
\end{tabular}

\subsection{Application to Analysis of Pharmaceutical Formulations}

The proposed techniques were applied to the tablets and capsules. The ingredients in the tablets and capsules did not interfere in the experiments. The applicability of the proposed methods for the assay of FEX in formulations was examined by analyzing various formulations and the results are tabulated in Table 3 were compared to the official nonaqueous titration method for FEX and IRB [3] by means of $t$ and $F$-values at $95 \%$ confidence level. In all cases, the average results obtained by the proposed methods and official method were statistically identical, as the difference between the average values had no significance at $95 \%$ confidence level. The low values of RSD show the results are reproducible. The proposed methods are simple, sensitive and reproducible and can be used for routine analysis of FEX 
and IRB in pure form and in formulations. The commonly used additives such as starch, lactose, glucose, titanium dioxide, and magnesium stearate do not interfere with the assay procedures.

Table 3. Determination of FEX and IRB in different pharmaceutical formulations by the proposed and official methods.

\begin{tabular}{|c|c|c|c|}
\hline \multirow{2}{*}{ Formulation } & \multirow{2}{*}{ Label claim } & \multicolumn{2}{|l|}{$\%$ Recovery $^{\mathrm{a}} \pm \mathrm{SD}$} \\
\hline & & Proposed method & Official method [3] \\
\hline \multirow{3}{*}{ Fexodine $^{\mathrm{b}}$} & \multirow{3}{*}{60 mg FEX/cap } & $100.80 \pm 0.58$ & $99.71 \pm 0.52$ \\
\hline & & $t=1.72$ & $t=125$ \\
\hline & & $F=1.24$ & $t=1.25$ \\
\hline \multirow[b]{2}{*}{ Fenadin $-120^{\mathrm{c}}$} & \multirow[b]{2}{*}{$120 \mathrm{mg} \mathrm{FEX/tab}$} & $100.50 \pm 0.85$ & $99.69 \pm 0.55$ \\
\hline & & $t=1.31$ & $t-124$ \\
\hline \multirow{3}{*}{ Fenadin $-180^{\mathrm{c}}$} & \multirow{3}{*}{$180 \mathrm{mg} \mathrm{FEX/tab}$} & $102.40 \pm 0.81$ & $100.52 \pm 0.64$ \\
\hline & & $t=2.48$ & $t=182$ \\
\hline & & $F=1.60$ & $l=1.82$ \\
\hline \multirow{3}{*}{ Rovil- $75^{\mathrm{c}}$} & \multirow{3}{*}{$75 \mathrm{mg} \mathrm{IRB/tab}$} & $101.12 \pm 0.86$ & $100.39 \pm 0.91$ \\
\hline & & $t=1.94$ & $t=206$ \\
\hline & & $F=1.12$ & $4 \quad 2.00$ \\
\hline \multirow[t]{2}{*}{ Rovil-150 } & \multirow[t]{2}{*}{$150 \mathrm{mg} \mathrm{IRB/tab}$} & $t=1.76$ & $t=149$ \\
\hline & & $F=1.45$ & $l-1.49$ \\
\hline
\end{tabular}

${ }^{\text {a }}$ Five independent analyses. At $95 \%$ confidence level t-value is 2.776 and F-value is $6.26 .{ }^{b}$ Supplied by KIMI, Syria and ${ }^{\mathrm{c}}$ supplied by BPI, Syria.

\section{Conclusion}

The developed spectrophotometric method describes the use of extractive ion-pair complexation reaction with acid dye for the determination of FEX and IRB in pure form and pharmaceutical formulations. The proposed method is accurate, precise and use simple and lower reagent consumption. Therefore, this approach could be considered for the analysis of FEX and IRB in the quality control laboratories. Method is sufficiently sensitive to permit determination even down to 0.013 and $0.75 \mu \mathrm{g} \mathrm{mL}{ }^{-1}$ of FEX and IRB, respectively. The sample recoveries from all formulations were in good agreement with their respective label claims, which suggested non-interference of formulation excipients in the estimation. The commonly used additives such as starch, lactose and magnesium stearate do not interfere with the assay procedures.

\section{References}

[1] Maryadele J, Neil JO, The Merck Index: An Encyclopedia of Chemicals, Drugs and Biologicals, $15^{\text {th }}$ ed., Royal Society of Chemistry, Cambridge, UK, 2013.

[2] Rita Breier A, Nudelman NS, Steppe M, Schapoval EES, Isolation and structure elucidation of photodegradation products of fexofenadine. Journal of Pharmaceutical and Biomedical Analysis, 2008, 46, pp. 250-257.

[3] British Pharmacopœia, Her Majesty Stationery Officer, London, UK, 2013.

[4] United States Pharmacopoeial Convention Inc. Rockville, 2011.

[5] Breier AR, Paim SC, Menegola J, Steppe M, Schapoval EE, Development and validation of a liquid chromatographic method for fexofenadine hydrochloride in capsules. Journal of
AOAC International, 2004, 87 (5), pp. 1093-1097.

[6] Maher HM, Sultan MA, Olah IV, Development of validated stability-indicating chromatographic method for the determination of fexofenadine hydrochloride and its related impurities in pharmaceutical tablets. Chemistry Central Journal, 2011, 5 (76), pp. 1-10.

[7] Arayne MS, Shehnaz H, Sultana N, Haider A, RP-HPLC method for the quantitative determination of fexofenadine hydrochloride in coated tablets and human serum. Medicinal Chemistry Research, 2011, 20 (1), pp. 55-61.

[8] Kozan I, Palabiyik IM, Karacan E, Onur F, Spectrophotometric and high performance liquid chromatographic determination of fexofenadine hydrochloride in pharmaceutical formulations. Turkish Journal of Pharmaceutical Sciences, 2008, 5 (3), pp. 175-189.

[9] Gazy AA, Mahgoub H, El-Yazbi FA, El-Sayed MA, Youssef $\mathrm{RM}$, Determination of some histamine H1-receptor antagonists in dosage forms. Journal of Pharmaceutical and Biomedical Analysis, 2002, 30 (3), pp. 859-867.

[10] Suresh Kumar K, Ravichandran V, Mohan Maruga Raja MK, Thyagu R, Dharamsi A, Spectrophotometric determination of fexofenadine hydrochloride. Indian Journal of Pharmaceutical Sciences, 2006, 68 (2), pp. 841-842.

[11] Rajput SJ, Parekh PR, Spectrophotometric determination of fexofenadine hydrochloride in bulk drug and in its dosage form. Eastern Pharmacist, 2001, 44 (527), pp. 101-103.

[12] Polawar PV, Shivhare UD, Bhusari KP, Mathur VB, Development and validation of spectrophotometric method of analysis for fexofenadine. Research Journal of Pharmacy and Technology, 2008, 1 (4), pp. 539-541.

[13] Ashour S, Khateeb M, Mahrouseh R, Extractive spectrophotometric and conductometric methods for determination of fexofenadine hydrochloride in pharmaceutical dosage forms. Pharmaceutica Analytica Acta, 2013, S2, pp. 1-6. 
[14] Amin AS, Ahmed IS, Mohamed HA, Utility of extracted colored ion-associate complexes formation reaction for the determination of fexofenadine hydrochloride in pure forms and in dosage forms. Journal of Chemical Engineering \& Process Technology, 2010, 1 (1), pp. 1-4.

[15] Alothman ZA, Bukhari N, Haider S, Wabaidur SM, Alwarthan AA, Spectrofluorimetric determination of fexofenadine hydrochloride in pharmaceutical preparation using silver nanoparticles. Arabian Journal of Chemistry, 2010, 3 (4), pp. 251-255.

[16] Abbas MN, Abdel Fattah AA, Zahran E, A novel membrane sensor for histamine H1-receptor antagonist fexofenadine. Analytical Sciences, 2004, 20 (8), pp. 1137-1142.

[17] Mikuš P, Valášková I, Havránek F, Determination of fexofenadine in tablets by capillary electrophoresis in free solution and in solution with cyclodextrins as analyte carriers. Drug Development and Industrial Pharmacy, 2005, 31 (8), pp. 795-801.

[18] Breier AR, Garcia SS, Jablonski A, Steppe M, Schapoval EES, Capillary electrophoresis method for fexofenadine hydrochloride in capsules. Journal of AOAC International, 2005, 88 (4), pp. 1059-1063.

[19] Zarapkar SS, Bhandari NP, Halkar UP, Simultaneous determination of fexofenadine hydrochloride and pseudoephedrine sulfate in pharmaceutical dosage by reverse phase high performance liquid chromatography. Indian Drugs, 2000, 37 (9), pp. 421-425.

[20] Radhakrishna T, Reddy GO, Simultaneous determination of fexofenadine and its related compounds by HPLC. Journal of Pharmaceutical and Biomedical Analysis, 2002, 29 (4), pp. 681-690.

[21] Vekaria H, Limbasiya V, Patel P, Development and validation of RP-HPLC method for simultaneous estimation of montelukast sodium and fexofenadine hydrochloride in combined dosage form. Journal of Pharmaceutical Research, 2013, 6 (1), pp. 134-139.

[22] Karakuş S, Küçükgüzel İ, Güniz Küçükgüzel Ş, Development and validation of a rapid RP-HPLC method for the determination of cetirizine or fexofenadine with pseudoephedrine in binary pharmaceutical dosage forms. Journal of Pharmaceutical and Biomedical Analysis, 2008, 46 (2), pp. 295-302.

[23] Arayne MS, Sultana N, Zeeshan MA, Siddiqui FA, Simultaneous determination of gliquidone, fexofenadine, buclizine, and levocetirizine in dosage formulation and human serum by RP-HPLC. Journal of Chromatographic Sciences, 2010, 48 (5), pp. 382-385.

[24] Tandulwadkar SS, More SJ, Rathore AS, Nikam AR, Sathiyanarayanan L, Kakasaheb R, Method development and validation for the simultaneous determination of fexofenadine hydrochloride and montelukast sodium in drug formulation using normal phase high-performance thin-layer chromatography. ISRN Analytical Chemistry, 2012, pp. 1-7.

[25] Mahgoub H, Gazy AA, El-Yazbi FA, El-Sayed MA, Youssef RM, Spectrophotometric determination of binary mixtures of pseudoephedrine with some histamine $\mathrm{H}_{1}$-receptor antagonists using derivative ratio spectrum method. Journal of Pharmaceutical and Biomedical Analysis, 2003, 31 (4), pp. 801-809.
[26] Maggio RM, Castellano PM, Vignaduzzo SE, Kaufman TS, Alternative and improved method for the simultaneous determination of fexofenadine and pseudoephedrine in their combined tablet formulation. Journal of Pharmaceutical and Biomedical Analysis, 2007, 45 (5), pp. 804-810.

[27] Vekaria HJ, Muralikrishna KS, Patel GF, Development and validation of spectrophotometric method for estimation of fexofenadine hydrochloride and montelukast sodium in combined dosage form. Pharmaceutical Analysis \& Quality Assurance, 2011, 4, pp. 197-199.

[28] Li JM, Wu Q, Wang LL, Assay of irbesartan tablets by HPLC. Yaowu Fenxi Zazhi, 2001, 21 (4), pp. 249-250.

[29] Goswami N, A validated stability-indicating liquid chromatographic method for determination of process related impurities and degradation behavior of irbesartan in solid oral dosage. Journal of Advanced Pharmaceutical Technology \& Research, 2014, 5 (1), pp. 33-40.

[30] Ganesan M, Nanjundan S, Gomathi M, Muralidharan S, Method development and validation of irbesartan using LCMS/MS: Application to pharmacokinetic studies. Journal of Chemical and Pharmaceutical Research, 2010, 2, pp. 740-746.

[31] Praveen KM, Sreeramulu J, Development and validation of a stability-indicating RP-HPLC method for assay of irbesartan in pure and pharmaceutical dosage form. International Journal of Pharmaceutical Sciences Review and Research, 2011, 6 (10), pp. 94-99.

[32] Mbah CJ, Kinetics of decomposition of irbesartan in aqueous solutions determined by high performance liquid chromatography. Pharmazie, 2004, 29 (12), pp. 920-922.

[33] Abdellatef HE, Extractive-spectrophotometric determination of disopyramide and irbesartan in their pharmaceutical formulation. Spectrochimica Acta Part A, 2007, 66 (4-5), pp. $1248-1254$.

[34] Rahman N, Siddiqui MR, Azmi SNH, Quantitative analysis of irbesartan in commercial dosage forms by kinetic spectrophotometry. Chemical and Pharmaceutical Bulletin, 2006, 54 (5), pp. 626-631.

[35] Ganesh K, Balraj C, Elango KP, Spectroscopic and spectrofluorimetric studies on the interaction of irbesartan with 2,3-dichloro-5,6-dicyano-1,4-benzoquinone and iodine. Spectrochimica Acta Part A, 2011, 79 (5), pp. 1621-1629.

[36] Kulsum S, Padmalatha M, Kumar E, Sruthi M, Vidyasagar G, Spectrophotometric methods for the determination of irbesartan in pure and pharmaceutical dosage forms. Research Journal of Pharmacy and Technology, 2011, 4 (10), pp. 1567-1569.

[37] Sane RT, Francis M, Pawar S, Determination of irbesartan in pharmaceutical dosage forms by HPTLC. Indian Drugs, 2002, 39 (1), pp. 32-35.

[38] Alanazi AM, Abdelhameed AS, Khalil NY, Khan AA, Darwish IA, HPLC method with monolithic column for simultaneous determination of irbesartan and hydrochlorothiazide in tablets. Acta Pharmaceutica, 2014, 64 (2), pp. 187-198.

[39] Hafez HM, Elshanawane AA, Abdelaziz LM, Kamal MM, Quantitative determination of three angiotensin-II-receptor antagonists in presence of hydrochlorothiazide by RP-HPLC in their tablet preparations. Iranian Journal of Pharmaceutical Research, 2013, 12 (4), pp. 635-43. 
[40] Ebeid WM, Elkady EF, El-Zaher AA, El-Bagary RI, Patonay $\mathrm{G}$, Synchronized separation of seven medications representing most commonly prescribed antihypertensive classes by using reversed-phase liquid chromatography: Application for analysis in their combined formulations. Journal of Separation Science, 2014, 37 (7), pp. 748-757.

[41] Pachauri S, Paliwal S, Srinivas KS, Singh Y, Jain V, Development and validation of HPLC method for analysis of some antihypertensive agents in their pharmaceutical dosage forms. Journal of Pharmaceutical Sciences and Research, 2010, 2, pp. 459-464.

[42] Rane VP, Patil KR, Sangshetti JN, Yeole RD, Shinde DB, Stability indicating LC method for simultaneous determination of irbesartan and hydrochlorothiazide in pharmaceutical preparations. Journal of Chromatographic Science, 2010, 48 (7), pp. 595-600.

[43] Sultana N, Arayne MS, Ali SS, Sajid S, Simultaneous determination of olmesartan medoxomil and irbesartan and hydrochlorothiazide in pharmaceutical formulations and human serum using high performance liquid chromatography. $\mathrm{Se} \mathrm{Pu,} \mathrm{2008,} 26$ (5), pp. 544-549.

[44] Ramzia IEB, Hanaa MH, Waleed AE, Spectrofluorometric, spectrophotometric and LC determination of irbesartan. Journal of Chemical and Pharmaceutical Research, 2011, 3, pp. $722-733$.

[45] Vujić Z, Mulavdić N, Smajić M, Brborić J, Stankovic P, Simultaneous analysis of irbesartan and hydrochlorothiazide: an improved HPLC method with the aid of a chemometric protocol. Molecules, 2012, 17, pp. 3461-3474.

[46] Vetuschi C, Giannandrea A, Carlucci G, Mazzeo P, Determination of hydrochlorothiazide and irbesartan in pharmaceuticals by fourth-order UV derivative spectrophotometry. IL Farmaco, 2005, 60 (8), pp. 665-670.

[47] Erk N, Three new spectrophotometric methods applied to the simultaneous determination of hydrochlorothiazide and irbesartan. Pharmazie, 2003, 58 (8), pp. 543-548.

[48] Albero I, Ródenas V, García S, Sánchez-Pedreño C, Determination of irbesartan in the presence of hydrochlorothiazide by derivative spectrophotometry. Journal of Pharmaceutical and Biomedical Analysis, 2002, 29 (1-2), pp. 299-305.

[49] Fayez YM, Simultaneous determination of some antihypertensive drugs in their binary mixture by novel spectrophotometric methods. Spectrochimica Acta Part A, 2014, 132, pp. 446-451.
[50] Joseph Charles J, Brault S, Boyer C, Langlois MH, Cabrero L, Dubost JP, Simultaneous determination of irbesartan and hydrochlorothiazide in tablets by derivative spectrophotometry. Analytical Letters, 2003, 36 (11), pp. 2485-2495.

[51] Hillaert S, Van-den-Bossche W, Simultaneous determination of hydrochlorothiazide and several angiotensin-II-receptor antagonists by capillary electrophoresis. Journal of Pharmaceutical and Biomedical Analysis, 2003, 31 (2), pp. 329-339.

[52] Hillaert S, Van den Bossche W, Optimization and validation of a capillary zone electrophoretic method for the analysis of several angiotensin-II-receptor antagonists. Journal of Chromatography A, 2002, 979 (1-2), pp. 323-333.

[53] Ashour S, Shehna MF, Bayram R, Spectrophotometric determination of alfuzosin $\mathrm{HCl}$ in pharmaceutical formulations with some sulphonephthalein dyes. International Journal of Biomedical Science, 2006, 2 (3), pp. 273-278.

[54] Ashour S, Alkhalil R, Simple extractive colorimetric determination of levofloxacin by acid-dye complexation methods in pharmaceutical preparations. IL Farmaco, 2005; 60, pp. 771-775.

[55] Sastry CSP, Rama Rao K, Siva Prasad D, Extractive spectrophotometric determination of some fluoroquinolone derivatives in pure and dosage forms. Talanta, 1995, 42, pp. 311-316.

[56] Rose J, Advanced physico-chemical experiments, Pittman, London, 1964, 67.

[57] Erk N, Extractive spectrophotometric methods for the novel antidepressant drug in bulk and pharmaceutical dosage forms by using bromthymol blue and bromcresol green. Analytical Letters, 2003, 36, pp. 1183-1196.

[58] Miller JN, Miller JC, Statistics and Chemometrics For Analytical Chemistry, Chapman \& Hall/CRC, London, UK, $5^{\text {th }}$ edition, 2005.

[59] Long GL, Winefordner JD, Limit of detection. a closer look at the IUPAC definition. Analytical Chemistry, 1983, 55 (7), pp. 712A-721A.

[60] Ringbom A, Zeitschrift Analytische Chemie, 1939, pp. 115332. 